\title{
Treatment with pravastatin attenuates progression of chronic pancreatitis in rat
}

\author{
Limin Wei $^{1}$, Mitsuyoshi Yamamoto ${ }^{1}$, Masaru Harada ${ }^{1}$ and Makoto Otsuki ${ }^{1,2}$
}

As appropriate therapies for pancreatic fibrosis and inflammation are limited, prognosis of chronic pancreatitis has not improved to date. Recent studies have shown that statins improve inflammation and fibrosis in several organs. We therefore examined the therapeutic effect of pravastatin on progression of chronic pancreatitis by starting this treatment after induction of pancreatic fibrosis in rats. Chronic pancreatitis was induced by continuous pancreatic ductal hypertension (PDH) for 14 days according to our previous study. Pravastatin at a dose of $10 \mathrm{mg} / \mathrm{kg} /$ day was administrated directly into the duodenum via cannula from 2 days after induction of PDH. Progression of pancreatic fibrosis and expression levels of transforming growth factor- $\beta 1$ and tumor necrosis factor- $\alpha$ mRNA were markedly attenuated after commencement of pravastatin compared with untreated group with PDH. In addition, pravastatin treatment markedly improved pancreatic exocrine function and significantly elevated expression level of interleukin (IL)-10 and superoxide dismutase activity in the pancreas compared with the untreated group with PDH. These results revealed that pravastatin substantially attenuates the progression of pancreatic inflammation, fibrosis and exocrine dysfunction probably by its anti-oxidative property and overproduction of IL-10 in animal model of chronic pancreatitis. These results provide an experimental evidence that pravastatin exerts beneficial effect for progression of chronic pancreatitis.

Laboratory Investigation (2011) 91, 872-884; doi:10.1038/labinvest.2011.41; published online 7 March 2011

KEYWORDS: fibrosis; HMG-CoA reductase; inflammation; oxidative stress; pancreas

Chronic pancreatitis is considered to be one of the intractable pancreatic diseases, because pancreatic fibrosis is progressive and irreversible, and beneficial therapies are lucking. Statins are competitive inhibitors of 3-hydroxy-3-methylglutarylcoenzyme A (HMG-CoA) reductase, the key enzyme that regulates the synthesis of cholesterol from mevalonic acid by suppressing the conversion of HMG-CoA. ${ }^{1}$ Therefore, statins are widely used in the first-line management of hyperlipidemia due to their efficacy in improving plasma lipid profiles. ${ }^{1}$ However, as mevalonate is the precursor not only of cholesterol, but also of many non-steroidal compounds, inhibition of HMG-CoA by statins may result in pleiotropic effects such as anti-inflammatory, ${ }^{2}$ anti-fibrotic ${ }^{3}$ and antioxidative $^{4}$ actions.

Previous studies have shown that statins improve inflammation and fibrosis in several organs in vivo such as the kidney, ${ }^{3,5,6}$ cardiovascular system ${ }^{7,8}$ and liver. ${ }^{9}$ However, in these studies, statins are administrated from before onset of inflammation and fibrosis, it therefore remains unclear as to whether statins exert therapeutic or preventive effects on inflammation and fibrosis in these organs. We recently showed that administration of pravastatin even after the onset of pancreatic fibrosis markedly improved pancreatic inflammation and fibrosis in the Otsuka Long-Evans Tokushima Fatty (OLETF) rat. $^{10}$ These results suggest a possibility that statins exert therapeutic effects for chronic pancreatitis.

We previously developed experimental model of chronic pancreatitis by inducing continuous pancreatic ductal hypertension (PDH) in rats. ${ }^{11}$ In this experimental model, marked inflammatory cells and fibrosis infiltrate into the pancreas, and pancreatic exocrine function markedly deteriorates. As these pathophysiological changes of this rat model closely resemble human chronic pancreatitis, this experimental model seems to be useful for investigating therapeutic strategies for chronic pancreatitis.

In this study, we therefore examined whether pravastatin exerts therapeutic effects on the progression of chronic pancreatitis in this experimental model, even if treatment with pravastatin started after induction of pancreatic fibrosis in rats.

\footnotetext{
${ }^{1}$ The Third Department of Internal Medicine, University of Occupational and Environmental Health, Japan School of Medicine, Kitakyushu, Japan and 2Department of Nutrition and Lifestyle-Related Diseases, Graduate School of Life Science, Kobe Women's University, Kobe, Japan Correspondence: Dr M Yamamoto, MD, PhD, 1-1 Iseigaoka, Yahatanishi-ku, Kitakyushu 807-8555, Japan.

E-mail: m-yamamo@med.uoeh-u.ac.jp

Received 6 February 2010; revised 9 September 2010; accepted 15 September 2010
} 


\section{MATERIALS AND METHODS Materials}

Pravastatin, a competitive inhibitor of HMG-CoA, was a generous gift from Daiichi-Sankyo (Tokyo, Japan).

\section{Animals}

Male wistar rats weighing 330-360 g were used, and maintained in a temperature $\left(23 \pm 2^{\circ} \mathrm{C}\right)$ - and humidity $(55 \pm 5 \%)$ controlled room with a 12:12-h light-dark cycle (lights on at $0700 \mathrm{~h}$ ), and received human care according to the guidelines at our institution. This experimental protocol was approved by our institutional animal welfare committee.

\section{Animal Preparation}

The rats were anesthetized with pentobarbital sodium $(50 \mathrm{mg}$ per kg body wt., intraperitoneal), and a midline incision of the abdomen was made. The common bile duct was ligated proximal to the pancreas near the liver, and a cannula was inserted above the ligature to collect pure bile. Another cannula was inserted into the biliopancreatic duct through the ampulla of Vater to collect pure pancreatic juice (PJ). An additional cannula was inserted into the duodenum to return biliopancreatic juice by a servomechanism and to administrate pravastatin or vehicle. After surgery, the rats were placed into a modified Bollman-type restraint cage. ${ }^{11}$ Surgical procedures were conducted according to the method of Green et al. ${ }^{12}$ During the recovery and experimental periods, the rats had full access to food and water ad libitum.

\section{Experimental Protocol}

The rats were divided into three groups. The first group received PDH with pravastatin treatment (PDH-P group, $n=24)$. The second group received $\mathrm{PDH}$ with vehicle during experimental period (PDH-C group, $n=24$ ). The third group was subjected to the same surgical procedure, but did not receive PDH and pravastatin treatment (CONT group, $n=32$ ) (Figure 1). On postoperative day 3, PDH was induced by raising the free end of the pancreatic duct cannula to vertical position at $10 \mathrm{~cm}$ above the pancreas to exert a hydrostatic pressure. The schematic diagram of the experimental model is shown in Figure 2, and details with regard to this experimental model were described previously. ${ }^{11} \mathrm{PDH}$ was increased by raising the free end of pancreatic cannula $2.5 \mathrm{~cm}$ each day until $15 \mathrm{~cm}$. Thereafter, we gradually decreased PDH to preserve pancreatic secretion. Serial change of pancreatic ductal pressure during experimental period for induction of chronic pancreatitis (Figure 3A) was selected according to our previous study. ${ }^{11}$ Pravastatin at a dose of $10 \mathrm{mg}$ per $\mathrm{kg}$ per day was administrated directly into the duodenum via cannula from 2 days after induction of PDH until the end of experimental period for 12 days (Figure 1). The dose of pravastatin was selected based on the previous studies. ${ }^{3,10}$ The PJ samples were taken before and at every 2 days after induction of PDH, and were analyzed for volume and amylase activity. Blood samples were taken before and on

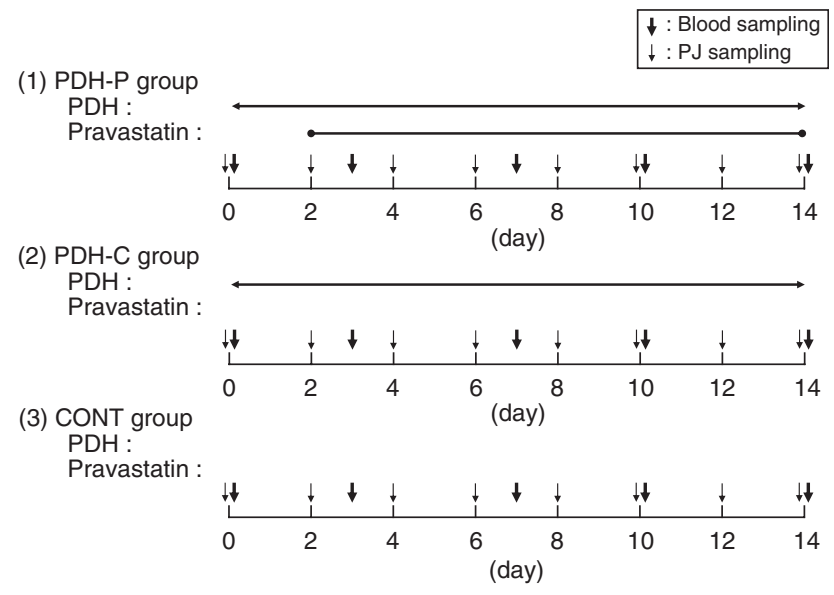

Figure 1 Experimental design. Pancreatic ductal hypertension with pravastatin treatment (PDH-P) group received $\mathrm{PDH}$ and treatment with pravastatin during experimental period. $\mathrm{PDH}-\mathrm{C}$ group received continuous PDH alone during experimental period. Control (CONT) group did not receive $\mathrm{PDH}$ and treatment with pravastatin. $\rightarrow$ and $\cdots$ indicate the duration of PDH and treatment with pravastatin, respectively. In addition, $\downarrow$ and $\downarrow$ indicate the time points of pancreatic juice (PJ) and blood sampling, respectively.

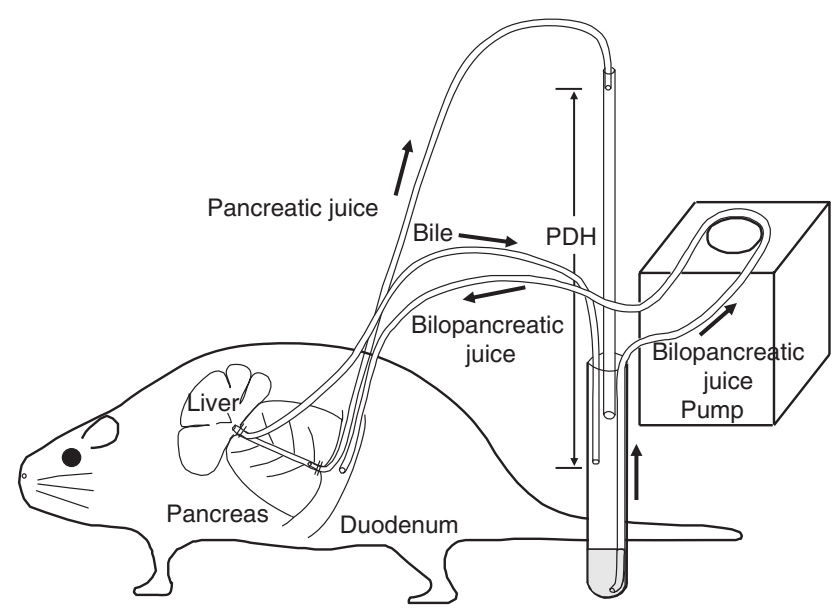

Figure 2 Schematic diagram of the experimental setup. Details with regard to the schematic diagram of the experimental model were previously described in ref. 11. Figure 2 is used with permission.

days 3, 7, 10 and 14 after induction of PDH to determine serum amylase activity (Figure 1). On days 2, 7 and 14 after induction of $\mathrm{PDH}$, rats were killed and the pancreas was taken under pentobarbital anesthesia $(50 \mathrm{mg}$ per kg body wt., intraperitoneal). Blood and PJ samples were taken at the same interval and the pancreas was removed on days $0,2,7$ and 14 from the CONT group of rats. A splenic portion of the pancreas was used for histological examination, and a duodenal portion of the pancreas was used for mRNA analysis, determination of contents of protein and DNA, and activities of amylase, superoxide dismutase (SOD) and tissue myeloperoxidase (MPO) in the pancreas. A duodenal 

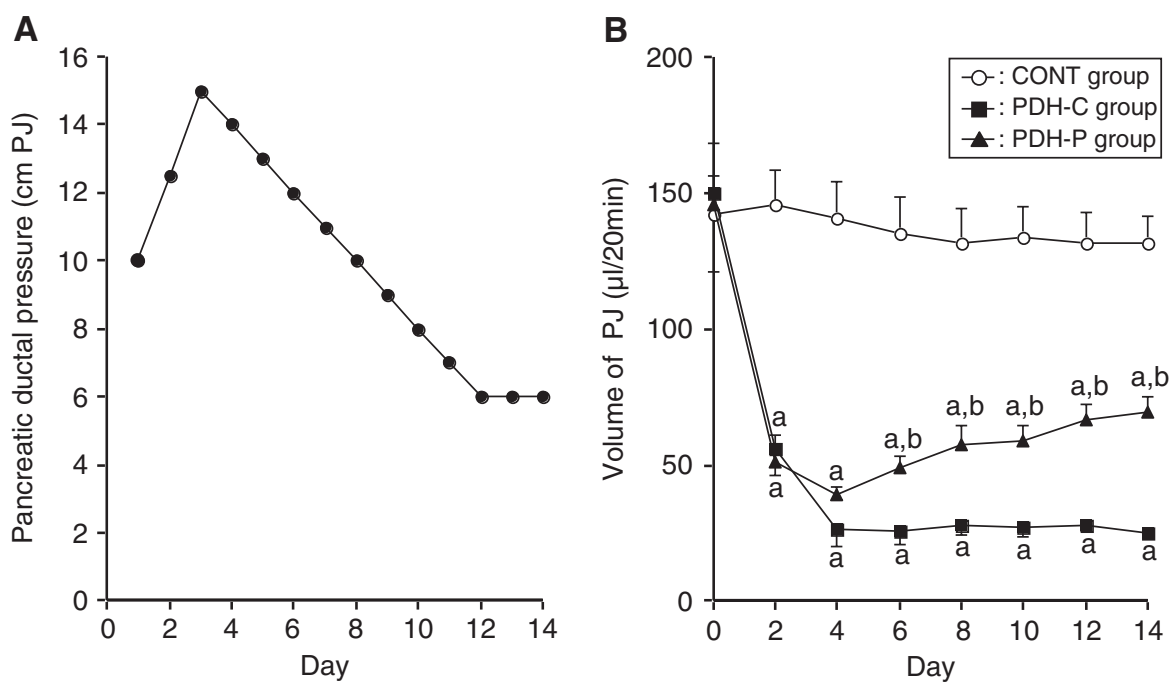

Figure 3 (A) Serial changes of the height of the pancreatic cannula from the pancreas in rats during the experimental period. The height of the free end of the pancreatic cannula represents pancreatic ductal pressure. Pancreatic ductal hypertension (PDH) was induced by vertically raising the free end of the pancreatic duct cannula. PDH was peaked on day 3, and was thereafter gradually decreased. (B) Serial changes of the volume of pancreatic juice (PJ). Volume of PJ in the PDH-C and PDH-P groups markedly decreased after induction of PDH. However, volume of PJ in the PDH-P group gradually increased after administration of pravastatin. Values are expressed as mean \pm s.e.m. of eight rats. (a) $P<0.05$ vs value in the CONT group at each time point. (b) $P<0.05$ vs value in the PHD-C group at each time point. Statistical analysis was performed by unpaired Student's $t$-test. For key to the groups, see Figure 1.

portion of the pancreas, serum and PJ were frozen at $-80^{\circ} \mathrm{C}$ until assays.

\section{Assays}

Duodenal portion of the pancreas was homogenized in a $0.15 \mathrm{M}$ sodium chloride solution using a motor-driven, Teflon-coated glass homogenizer, and the homogenates were filtered through three layers of gauze and then sonicated for $1 \mathrm{~min}$. The aqueous phase was used for amylase, protein and DNA assays. Protein concentration was measured using Folin phenol reagent with bovine serum albumin as a standard. ${ }^{13}$ Pancreatic DNA was measured fluorometrically by the reaction between 3, 5-diaminobenzoic acid and deoxyribose sugar using calf thymus DNA as a standard. ${ }^{14}$ Amylase activities in the pancreas, PJ and serum were determined by a chromogenic method with a Phadebas amylase test (Phadebas, Lund, Sweden). ${ }^{15}$ Bicarbonate concentration of PJ was determined by acidification of samples with $\mathrm{HCl}$ immediately after collection, followed by back-titration using the TIM840 multititration system (Radiometer Analytical, Villeurbanne, France). Activity of a primary antioxidant enzyme, SOD, in the pancreas was determined using watersoluble tetrazolium salt (SOD Assay Kit-WST; Dojindo Molecular Technologies, Kumamoto, Japan). ${ }^{16}$

\section{Physical Analysis}

The body weights of rats were measured after the induction of anesthesia before surgery and after the experimental period. Food intake was determined daily during the experimental period.

\section{Pancreatic Function Test}

On day 13 after induction of $\mathrm{PDH}$, pancreatic exocrine function in response to secretin was evaluated after an overnight fast. PDH was decompressed from $60 \mathrm{~min}$ before and during the pancreatic function test. Porcine secretin (Peptide Institute, Protein Research Foundation, Osaka, Japan) at a dose of $100 \mathrm{pmol} / \mathrm{kg}$ was given by a bolus injection into tail vein after obtaining basal PJ flow for $15 \mathrm{~min}$, and PJ was further collected for $45 \mathrm{~min}$ at $15 \mathrm{~min}$ intervals. The volume, bicarbonate concentration and amylase activity of PJ were determined.

\section{MPO Estimation}

Neutrophil sequestration in the pancreas was quantified by measuring MPO activity according to the previous study. ${ }^{17}$ Pancreatic samples were thawed and homogenized in $20 \mathrm{mM}$ phosphate buffer ( $\mathrm{pH}$ 7.4). Samples were centrifuged $\left(10000 \mathrm{~g} / \mathrm{min}, 4^{\circ} \mathrm{C}\right)$, and the resulting pellet was resuspended in $50 \mathrm{mM}$ phosphate buffer ( $\mathrm{pH}$ 6.0) containing $0.5 \%$ hexadecyltrimethylammonium bromide (Sigma, St Louis, MO, USA). The suspension was subjected to three cycles of freezing and thawing, and disruptured by sonication. The sample was then centrifuged $\left(10000 \mathrm{~g} / \mathrm{min}, 4^{\circ} \mathrm{C}\right)$, and the supernatant was used for MPO assay. The reaction mixture consisted of supernatant, $1.6 \mathrm{mM}$ tetramethylbenzidine (Sigma), $80 \mathrm{mM}$ sodium phosphate buffer $(\mathrm{pH} 5.4)$ and $0.3 \mathrm{mM}$ hydrogen peroxide. This mixture was incubated at $37^{\circ} \mathrm{C}$ and the reaction was terminated with $2 \mathrm{M} \mathrm{H}_{2} \mathrm{SO}_{4}$. Then, absorbance was measured at $450 \mathrm{~nm}$ and corrected for the 
weight of the tissue sample, and compared with the CONT group (fold increase over CONT group).

\section{Hydroxyproline Assay}

The hydroxyproline assay was performed as a marker of collagen synthesis in the pancreas using the method described previously. ${ }^{18}$ The whole pancreatic tissues were homogenized in saline, hydrolyzed with $2 \mathrm{~N} \mathrm{NaOH}$ for $30 \mathrm{~min}$ at $120^{\circ} \mathrm{C}$, followed by the determination of hydroxyproline by modification of the Neumann and Logan's reaction using Chloramine $\mathrm{T}$ and Ehrlich's reagent ${ }^{19}$ using a hydroxyproline standard curve and measuring at $550 \mathrm{~nm}$. Values were expressed as $\mathrm{mg}$ of hydroxyproline per $\mathrm{g}$ pancreas.

\section{Quantitative Real-Time Reverse Transcription- Polymerase Chain Reaction}

The expression levels of a fibrogenic growth factor, transforming growth factor (TGF)- $\beta 1$, a proinflammatory cytokine, tumor necrosis factor (TNF)- $\alpha$, and an anti-inflammatory cytokine, interleukin (IL)-10 mRNA, were determined by quantitative TaqMan PCR with glyceraldehyde 3-phosphate dehydrogenase (GAPDH) gene as a reference. For real-time reverse transcription polymerase chain reaction, total RNA was extracted from frozen pancreatic tissue by the acid guanidium thiocyanate-phenol-chloroform method, ${ }^{20}$ and $2 \mu \mathrm{g}$ of total RNA were reverse transcribed using random hexamers and TaqMan RT reagents (Applied Biosystems, Foster City, CA, USA). PCR of TGF- $\beta 1$, TNF- $\alpha$, IL- 10 and $G A P D H$ were performed using the TaqMan probe, TaqMan universal PCR master mix and primers for TGF- $\beta 1$, TNF- $\alpha$ or IL-10, as well as TaqMan rodent GAPDH control reagents (Applied Biosystems). PCR products were amplified $\left(50^{\circ} \mathrm{C}\right.$ for $2 \mathrm{~min}$ and $95^{\circ} \mathrm{C}$ for $10 \mathrm{~min}$, followed by 40 cycles of $95^{\circ} \mathrm{C}$ for $15 \mathrm{~s}$ and $60^{\circ} \mathrm{C}$ for $1 \mathrm{~min}$ ) and analyzed on a real-time PCR cycler, the ABI PRISM 7000 sequence detection system (Applied Biosystems). For quantification, the fluorescence intensity was plotted against the PCR cycle number. The amplification cycle displaying the first significant increase of the fluorescence signal was defined as the threshold cycle $\left(C_{\mathrm{T}}\right)$. The $C_{\mathrm{T}}$ value of each sample was compared with $C_{\mathrm{T}}$ values of the standardization series. The amounts of TGF- $\beta 1$, TNF- $\alpha$ and IL-10 transcripts were normalized to the amount of GAPDH transcript in the same cDNA (expressed as fold change per GAPDH).

\section{Histological Examination}

A splenic portion of pancreatic tissue was fixed overnight in $4 \%$ buffered neutral paraformaldehyde solution, embedded in paraffin and deparaffinized by standard procedures. Thin sections $(5 \mu \mathrm{m})$ were stained with hematoxylin and eosin and Azan-Mallory staining for light microscopic examination. All histological analyses were performed in randomly selected fields of sections by two investigators blinded to the identity of the treatment groups.

\section{Immunohistochemistry for Detection of Activated Pancreatic Stellate Cells, Apoptotic Cells and Oxidatively Stressed Cells}

For the detection of activated pancreatic stellate cells (PSCs), apoptotic cells and oxidatively stressed cells in the pancreas, we conducted immunohistochemistry for $\alpha$-smooth muscle actin ( $\alpha$-SMA), a marker for activated PSCs, ${ }^{21}$ single-stranded regions in the DNA (ss-DNA) expressed in apoptotic cells $^{22}$ and 8-hydroxy-2'-deoxyguanosine (8-OHdG), a marker for the oxidative DNA damage. ${ }^{23}$ For immunohistochemistry for $\alpha$-SMA and ss-DNA, pancreatic tissue sections were immersed in PBS ( $\mathrm{pH}$ 7.2) for $10 \mathrm{~min}$ and then in PBS containing $3 \% \mathrm{H}_{2} \mathrm{O}_{2}$ for $10 \mathrm{~min}$ to quench endogenous peroxidases. After further incubation in $0.25 \%$ casein solution for $10 \mathrm{~min}$, the tissue sections were incubated with a specific primary antibody for $\alpha$-SMA (Dako Corporation, Carpinteria, CA, USA) diluted at 1:50, or a specific primary antibody for ss-DNA (Dako Corporation) diluted at 1:100 in PBS for $16 \mathrm{~h}$ at $4^{\circ} \mathrm{C}$. The primary antibodies were visualized by the labeled streptavidin-biotin method using a commercially available kit (Dako Corporation). For the detection of immunoreactive product of 8-OHdG, the avidinbiotin complex method with alkaline phosphatase was used as described previously. ${ }^{24}$ Pancreatic sections were autoclaved for $10 \mathrm{~min}$ at $121^{\circ} \mathrm{C}$ in $10 \mathrm{mM}$ citrate buffer ( $\mathrm{pH} \mathrm{6.0)}$. Then, the following were sequentially applied: normal rabbit serum (diluted at 1:75) (Dako Corporation) for inhibition of nonspecific binding of secondary antibody, N45.1, biotin-labeled rabbit anti-mouse immunoglobulin G serum (diluted at 1:300) (Japan Institute for the Control of Aging, Shizuoka, Japan) and avidin-biotin-alkaline phosphate complex (diluted at 1:100) (Vector Laboratories, Burlingame, CA, USA). All procedures were performed as recommended by the manufacturer.

\section{Quantitative Analysis of Apoptosis and Oxidative Stress in the Immunohistochemistry}

As immunoreactivity of ss-DNA and 8-OHdG are observed in the nuclear compartment, it is possible to quantify the immunoreactions in each experimental group. To determine indexes of ss-DNA and 8-OHdG in the pancreas, 20 nonoverlapping fields were randomly selected from five rats in each experimental group at $\times 200$ magnification. At least 300 acinar cells were counted in each field, and the indexes of ss-DNA and 8-OHdG represented the percentage of positive cells.

\section{Quantitative Analysis for Pancreatic Fibrosis in the Histological Examination}

Quantitative evaluation of fibrotic area in the pancreatic specimen was performed using an Axiophot microscope (Carl Zeiss, Eching, Germany) connected to an interactive image analysis system (IBAS, Carl Zeiss). Twenty non-overlapping fields with Azan-Mallory staining from five rats in each experimental group were randomly selected at $\times 100$ 
magnification. The blue-stained fibrotic area was determined by IBAS. The proportion of pancreatic fibrosis was indicated as equation: area of fibrosis/total area of specimen.

\section{Statistical Analysis}

Results were expressed as the mean \pm s.e.m. Statistical analysis was performed by unpaired Student's $t$-test, paired $t$-test or repeated measure one-way ANOVA followed by Fisher's protected least significant difference test as appropriate using the commercial software, StatView (Abacus Concepts/Brain Power, Berkeley, CA, USA). Differences with $P<0.05$ were considered as statistically significant.

\section{RESULTS}

\section{Physical Findings}

Body weight of the PDH-C group significantly decreased, whereas that of the CONT group significantly increased on day 14 compared with respective initial values on day 0 . Pravastatin treatment prevented the decrease in body weight of rats during experimental period (Table 1). Daily food intake of the PDH-C group significantly decreased on day 14 compared with that on day 0 , whereas the PDH-P group maintained similar levels during experimental period as well as the CONT group (Table 1). However, there were no significant differences in the average food intake during entire experimental period among all experimental groups.

Table 1 Effects of pravastatin treatment on body weight gain and daily food intake

CONT group $\quad \mathrm{PDH}-\mathrm{C}$ group $\quad \mathrm{PDH}-\mathrm{P}$ group

$\begin{array}{llll}\text { Body weight }(g) & & & \\ \text { Day 0 } & 359.5 \pm 8.8 & 362.0 \pm 11.2 & 349.3 \pm 10.8 \\ \text { Day 14 } & 386.7 \pm 8.8^{\mathrm{a}} & 340.7 \pm 8.5^{\mathrm{a}, \mathrm{b}} & 354.0 \pm 9.5 \\ \text { Difference } & +27.2 \pm 4.7 & -21.3 \pm 3.2^{\mathrm{b}} & +4.7 \pm 4.1^{\mathrm{b}, \mathrm{c}}\end{array}$

Food intake (g/day)

$\begin{array}{llll}\text { Day } 0 & 21.3 \pm 1.6 & 21.2 \pm 2.4 & 21.7 \pm 1.6 \\ \text { Day } 7 & 23.4 \pm 1.7 & 25.8 \pm 3.3 & 25.4 \pm 1.6 \\ \text { Day } 14 & 22.8 \pm 1.5 & 16.2 \pm 1.3^{\mathrm{b}} & 23.9 \pm 1.7 \\ \text { Average } & 22.5 \pm 0.9 & 22.7 \pm 0.7 & 22.4 \pm 0.6\end{array}$

Values were mean \pm s.e.m. of eight rats.

${ }^{\mathrm{a}}$ Significant difference between the value on days 0 and 14 in the same experimental group. Statistical analysis was performed by paired $t$-test. PDH-C group received continuous pancreatic ductal hypertension $(\mathrm{PDH})$ alone during experimental period. PDH-P group received continuous PDH and treatment with pravastatin during experimental period. CONT group did not received $\mathrm{PDH}$ and treatment with pravastatin.

${ }^{\mathrm{b}}$ Significant difference $v s$ the value of the CONT group.

${ }^{c}$ Significant difference vs the value of the PDH-C group. Statistical analysis was performed by unpaired Student's $t$-test.

\section{Serum and PJ Analysis}

$\mathrm{PDH}$ caused an immediate and significant decrease in volume of PJ flow. However, pravastatin treatment gradually restored PJ flow (Figure 3B). Amylase activity of PJ immediately and markedly decreased after induction of $\mathrm{PDH}$, and further decreased during the experimental period in the PDH-C group (Figure 4A). However, amylase activity of PJ in the PDH-P group gradually recovered after commencement of pravastatin treatment (Figure 4A). In the $\mathrm{PDH}-\mathrm{C}$ group, serum amylase activity gradually, but significantly, elevated after the induction of PDH compared with that in the CONT group and peaked on day 7 (Figure 4B). Pravastatin treatment prevented the significant increases in serum amylase activity after induction of PDH and maintained at similar levels of the CONT group (Figure 4B).

\section{Pancreatic Function Test}

The basal PJ volume (Figure 5A) and amylase activity of PJ (Figure $5 \mathrm{~B}$ ) in the $\mathrm{PDH}-\mathrm{C}$ and $\mathrm{PDH}-\mathrm{P}$ groups were significantly lower than those in the CONT group. A bolus injection of secretin at a dose of $100 \mathrm{pmol} / \mathrm{kg}$ failed to cause significant increases in PJ volume (Figure 5A), amylase activity of PJ (Figure 5B) and bicarbonate concentration of PJ (Figure 5C) in the PDH-C group. However, the same dose of secretin induced a significant increase in these parameters in the PDH-P group as well as in the CONT group (Figures $5 \mathrm{~A}-\mathrm{C}$ ).

\section{Pancreatic Weight, Contents of Protein and DNA, and Amylase Activity}

The pancreatic weight, contents of protein and DNA, and amylase activity of the PDH-C group significantly decreased compared with those of the CONT group (Table 2). However, these parameters of the PDH-P group were significantly higher than those of the PDH-C group (Table 2).

\section{Hydroxyproline Level, Activities of MPO and SOD, and Expression level of TNF- $\alpha$ and IL-10 mRNA in the Pancreas}

In the PDH-C group, hydroxyproline level and MPO activity were significantly increased, whereas SOD activity was significantly decreased compared with those in the CONT group (Table 3). Treatment with pravastatin significantly reversed these alterations (Table 3). The mRNA expressions of TNF- $\alpha$ and IL-10 in the PDH-C group were higher than those in the CONT group. Treatment with pravastatin significantly attenuated mRNA expression of TNF- $\alpha$, but markedly elevated mRNA expression of IL-10 compared with those in the PDH-C group (Table 3).

\section{Serial Changes of Proportion of Fibrotic Area and Expression Level of TGF- $\beta 1$ mRNA in the Pancreas}

Proportion of fibrotic area progressively increased in the PDH-C group until the end of experimental period. Treatment with pravastatin from day 2 significantly attenuated the 
A

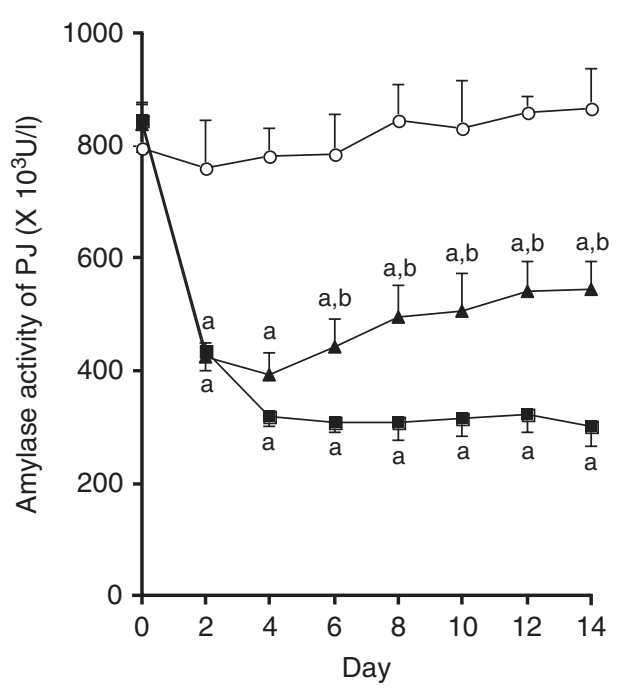

B

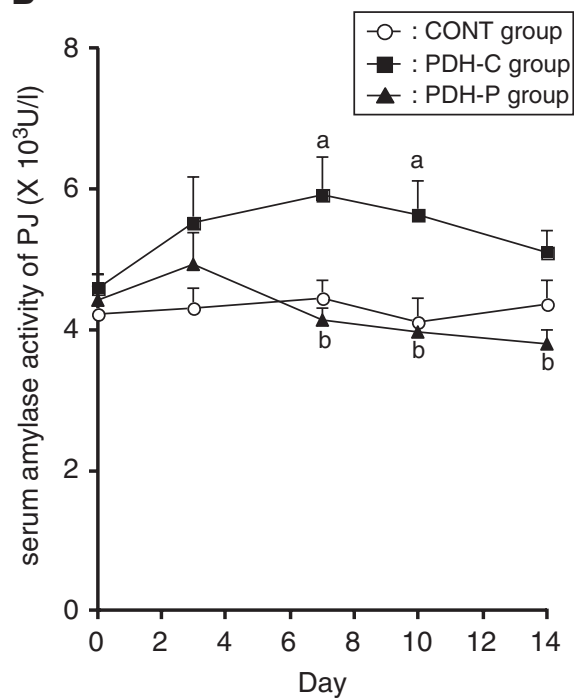

Figure 4 Serial changes of amylase activity of pancreatic juice (PJ) (A) and serum (B). (A) After induction of pancreatic ductal hypertension (PDH), amylase activity of PJ significantly decreased in the PDH-C and PDH-P groups compared with that in the control (CONT) group. However, administration of pravastatin gradually, but significantly, elevated amylase activity of PJ compared with the PDH-C group. (B) Serum amylase activity in the PDH-C group slightly, but significantly, increased after induction of PDH compared with that in the CONT group. However, treatment with pravastatin prevented the significant increase in serum amylase activity compared with the CONT group. Values are expressed as mean \pm s.e.m. of eight rats. (a) $P<0.05$ vs value in the CONT group at each time point. (b) $P<0.05$ vs value in the PDH-C group at each time point. Statistical analysis was performed by unpaired Student's $t$-test. For key to the groups, see Figure 1.
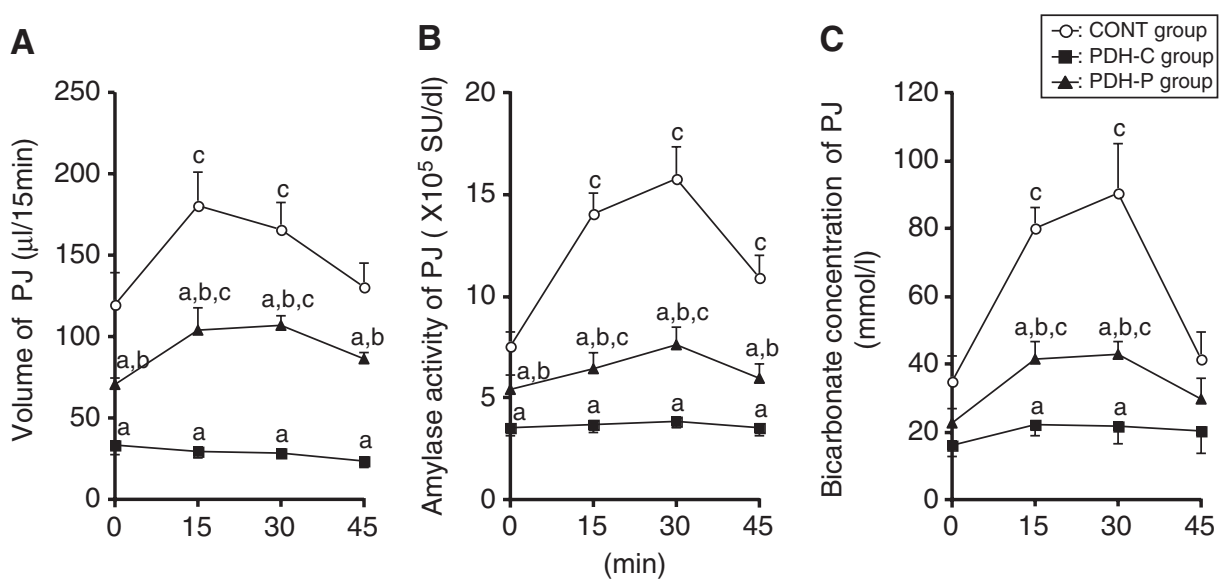

Figure 5 Changes in volume (A), amylase activity (B) and bicarbonate concentration of pancreatic juice (PJ) (C) in response to intravenous injection of secretin at $100 \mathrm{pmol} / \mathrm{kg}$. Both basal and secretin-stimulated PJ volume, amylase activity and bicarbonate concentration in the pancreatic ductal hypertension (PDH)-C group were markedly lower than those in the control (CONT) group. However, these parameters in the PDH-P group were significantly higher than those in the PDH-C group at almost all time points. Values are expressed as mean \pm s.e.m. of eight rats. (a) $P<0.05$ vs value in the CONT group at each time point. (b) $P<0.05$ vs value in the PHD-C group at each time point. Unpaired Student's $t$-test was used for statistical analysis. (c) $P<0.05$ vs basal value before injection of secretin (at time 0 ) in the same group. Statistical analysis was performed by repeated measure one-way analysis of variance (ANOVA) followed by Fisher's protected least significant difference test. For key to the groups, see Figure 1.

increase in proportion of fibrotic areas, although it showed a slight increase on day 14 (Figure 6A). Induction of PDH markedly increased the expression level of TGF- $\beta 1 \mathrm{mRNA}$ in the pancreas on day 2, but thereafter it gradually decreased in the PDH-C group (Figure 6B). Treatment with pravastatin further decreased the expression level of TGF- $\beta 1$ mRNA in the pancreas compared with the PDH-C group (Figure 6B).

\section{Histological Findings of the Pancreas}

In the CONT group, minimal histological changes were noted in the pancreas on day 14 (Figure 7A). However, in the PDH-C group, inflammatory cells were mainly infiltrated into the intralobular area and around pancreatic ducts on day 2 (Figure 7B). On day 14, fibrosis and inflammatory cells were markedly distributed in the interlobular and 
intralobular areas of the pancreas in the PDH-C group. In addition, exocrine glands of the pancreas were atrophic (Figure 7C). In contrast, although the pancreatic ducts were dilated owing to $\mathrm{PDH}$, distribution of fibrosis and inflammatory cells were markedly attenuated in the PDH-P group on day 14 (Figure 7D). Azan-Mallory staining clearly showed that blue-stained fibrotic area was rarely noted in the CONT group (Figure 7E). However, in the PDH-C group, fibrosis was observed mainly in the periductal area and slightly in the intralobular area on day 2 (Figure 7F). On day 14 , fibrotic areas were markedly distributed around pancreatic ducts, and in the interlobular and intralobular areas of the pancreas in the PDH-C group (Figure 7G). In the PDH-P group, fibrotic areas were mainly detected around the pancreatic ducts and were slightly found in the interlobular and intralobular areas of the pancreas on day 14 (Figure $7 \mathrm{H}$ ).

\section{Immunohistochemistry for Detection of Activated PSCs, Apoptotic Cells and Oxidatively Stressed Cells}

Expressions of $\alpha$-SMA, a marker for activated PSCs, were rarely detected, except in the vessel walls in the CONT group (Figure 8A). In the PDH-C group, $\alpha$-SMA-positive cells were markedly distributed in the periductal, periacinar and interlobular areas of the pancreas (Figure $8 \mathrm{~B}$ ). In contrast,

Table 2 Effects of pravastatin treatment on the pancreatic weight, contents of protein and DNA, and amylase activity

\begin{tabular}{lccc}
\hline & CONT group & PDH-C group & PDH-P group \\
\hline Pancreatic weight $(\mathrm{g})$ & $1.4 \pm 0.1$ & $1.1 \pm 0.1^{\mathrm{a}}$ & $1.3 \pm 0.2^{\mathrm{b}}$ \\
Protein content $(\mathrm{mg})$ & $514.5 \pm 72.5$ & $316.4 \pm 21.1^{\mathrm{a}}$ & $406.3 \pm 25.4^{\mathrm{b}}$ \\
DNA content $(\mathrm{mg})$ & $5.5 \pm 0.9$ & $1.7 \pm 0.4^{\mathrm{a}}$ & $3.2 \pm 0.4^{\mathrm{a}, \mathrm{b}}$ \\
Amylase activity $\left(\times 10^{3} \mathrm{IU}\right)$ & $34.3 \pm 4.3$ & $8.4 \pm 0.9^{\mathrm{a}}$ & $15.6 \pm 2.3^{\mathrm{a}, \mathrm{b}}$ \\
\hline
\end{tabular}

Values were mean \pm s.e.m. of eight rats.

${ }^{\mathrm{a}}$ Significant difference $v s$ the value of the CONT group.

${ }^{\mathrm{b}}$ Significant difference $v$ s the value of the PDH-C group. Statistical analysis was performed by unpaired Student's $t$-test. For key to the groups, see Table 1.
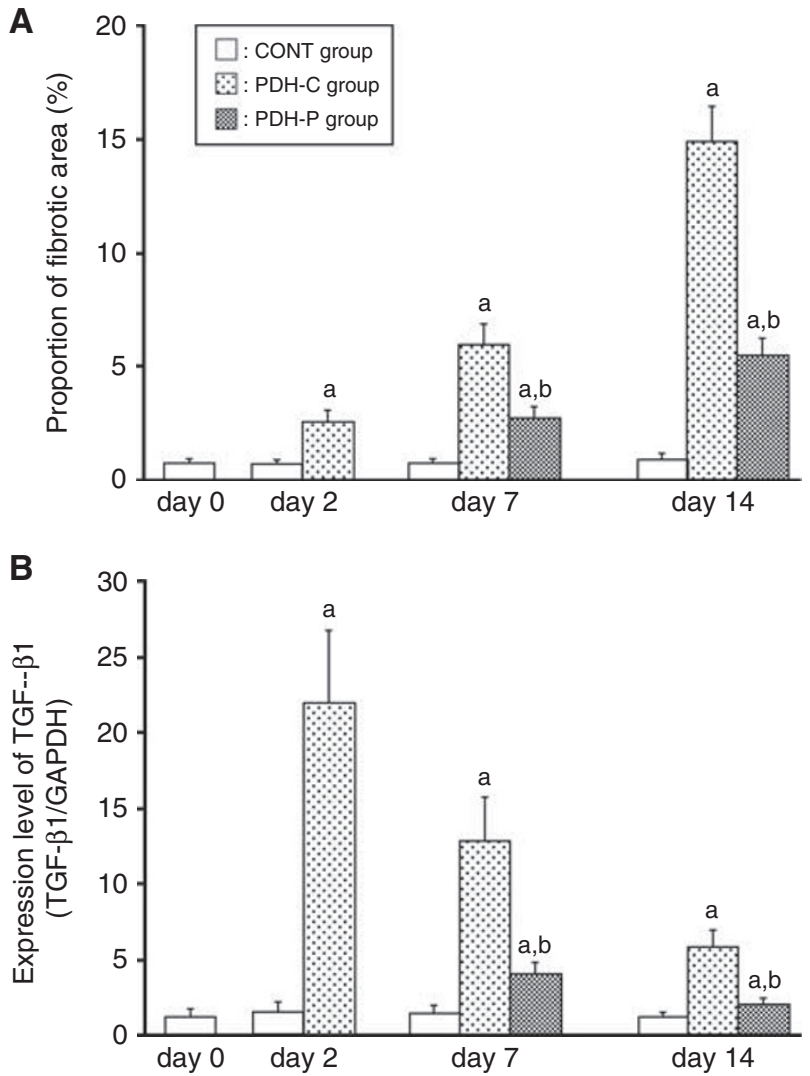

Figure 6 Serial changes of proportion of fibrotic area (A) and expression level of tumor growth factor (TGF)- $\beta 1$ mRNA (B) in the pancreas during experimental period. (A) In the pancreatic ductal hypertension (PDH)-C group, proportion of fibrotic area markedly increased with the duration of $\mathrm{PDH}$. Although proportion of fibrotic area gradually increased in the PDH-P group, these values were significantly lower than those in the PDH-C group at each time point. (B) The expression level of TGF- $\beta 1$ transcript in the pancreas markedly increased after induction of PDH. In the PDH-C group, the expression level of TGF- $\beta 1$ transcript peaked on day 2 , and thereafter, it gradually decreased. However, in the PDH-P group, the expression level of TGF- $\beta 1$ transcript in the pancreas significantly decreased compared with that in the PDH-C group. Values are expressed as mean \pm s.e.m. of eight rats. (a) $P<0.05$ vs value in the control (CONT) group at each time point. (b) $P<0.05$ vs value in the PHD-C group at each time point. Statistical analysis was performed by unpaired Student's $t$-test. For key to the groups, see Figure 1.

Table 3 Effects of pravastatin treatment on hydroxyproline level, activities of myeloperoxidase (MPO) and superoxide dismutase (SOD), and expression levels of tumor necrosis factor (TNF)- $\alpha$ and interleukin (IL)-10 mRNA in the pancreas

\begin{tabular}{|c|c|c|c|}
\hline & CONT group & $\mathrm{PDH}-\mathrm{C}$ group & PDH-P group \\
\hline Hydroxyproline level (mg/g pancreas) & $0.22 \pm 0.03$ & $0.80 \pm 0.09^{\mathrm{a}}$ & $0.38 \pm 0.05^{\mathrm{a}, \mathrm{b}}$ \\
\hline SOD activity $\left(\times 10^{3} \mathrm{U} / \mathrm{g}\right.$ pancreas $)$ & $1.80 \pm 0.12$ & $0.88 \pm 0.16^{\mathrm{a}}$ & $1.35 \pm 0.14^{\mathrm{a}, \mathrm{b}}$ \\
\hline TNF- $\alpha$ (TNF- $\alpha /$ GAPDH: fold increase over CONT group) & $1.00 \pm 0.08$ & $1.69 \pm 0.09^{\mathrm{a}}$ & $1.29 \pm 0.09^{a, b}$ \\
\hline
\end{tabular}

Values were mean \pm s.e.m. of eight rats.

a Significant difference vs the value of the CONT group.

${ }^{\mathrm{b}}$ Significant difference $v s$ the value of the PDH-C group. Statistical analysis was performed by unpaired Student's $t$-test. For key to the groups, see Table 1. 
$\alpha$-SMA-positive cells were slightly detected in the periductal and interlobular areas in the PDH-P group (Figure 8C).

Apoptotic cells detected with antibody for ss-DNA were rarely observed in the CONT group (Figure $8 \mathrm{D}$ ). In the $\mathrm{PDH}-\mathrm{C}$ group, several apoptotic cells were detected in one intralobular area, especially atrophic lesion of the pancreas (Figure $8 \mathrm{E}$ ), and index of ss-DNA was significantly increased compared with that in the CONT group (Table 4). Treatment with pravastatin decreased the number of apoptotic cells in the intralobular areas of the pancreas (Figure 8F) and significantly lowered the index of ss-DNA compared with the PDH-C group (Table 4).

Oxidatively stressed cells detected with nuclear staining for 8-OHdG were very rare in the CONT group (Figure 9A).
In contrast, in the PDH-C group, intense 8-OHdG immunoreactivity was observed, especially in the atrophic lesions of the pancreas (Figure 9B), and index of 8-OHdG was significantly higher than that in the CONT group (Table 4). However, immunoreactivity of $8-\mathrm{OHdG}$ was slightly detected in the PDH-P group (Figure 9C), and index of 8-OHdG in the PDH-P group was significantly lower than that in the PDH-C group (Table 4).

\section{DISCUSSION}

This study clearly showed that treatment with pravastatin, in spite of commencement after the induction of pancreatic fibrosis, attenuated progression of chronic pancreatitis in a rat experimental model. In this study, treatment with
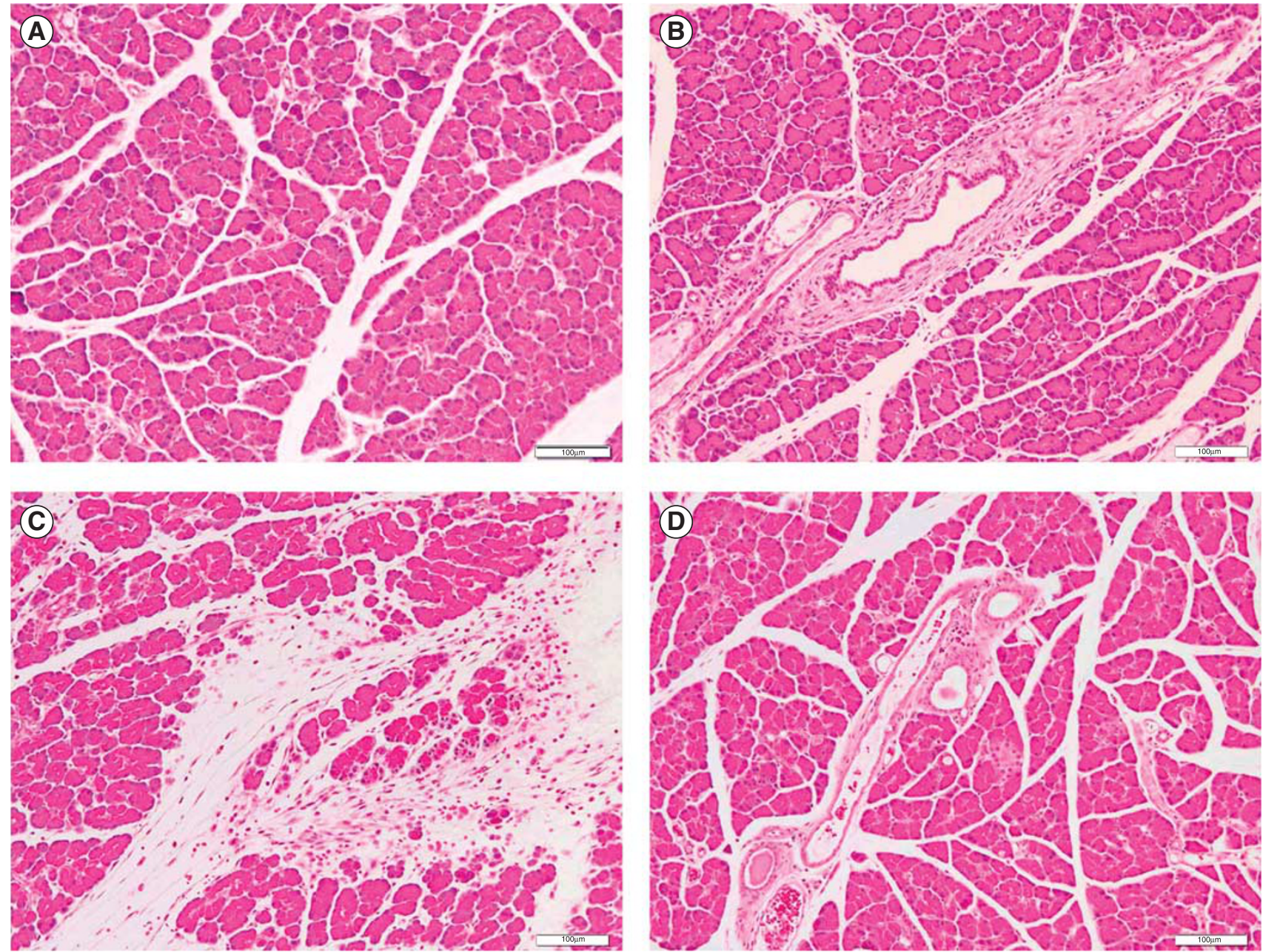

Figure 7 Representative light microscopic appearances of the pancreas stained with hematoxylin and eosin (H\&E) (A-D) and with Azan-Mallory staining (E-H) in the each experimental group. (A) Only minimal histological changes were observed in the control (CONT) group on day 14. (B) However, in the pancreatic ductal hypertension (PDH)-C group, infiltration of inflammatory cells was noted in the intralobular and periductal areas on day 2. (C) On day 14, the pancreas of the PDH-C group was atrophic, and fibrosis and inflammatory cells were markedly distributed in the interlobular and intralobular areas. (D) In contrast, distributions of inflammatory cells and fibrosis were slightly noted in the PDH-P group on day 14. (E): Azan-Mallory staining revealed that fibrosis was rarely noted in the CONT group on day 14. (F) In contrast, Azan-Mallory staining confirmed that fibrosis was slightly found in the periductal and intralobular areas in the PDH-C group on day 2. (G) On day 14, fibrosis was markedly distributed around pancreatic ducts and in the interlobular and intralobular areas in the PDH-C group. (H) However, fibrosis was noted mainly around pancreatic ducts, but was slightly noted in the interlobular and intralobular areas in the PDH-P group. Original magnification, $\times 100$. Scale bar indicates $100 \mu \mathrm{m}$. For key to the groups, see Figure 1. 

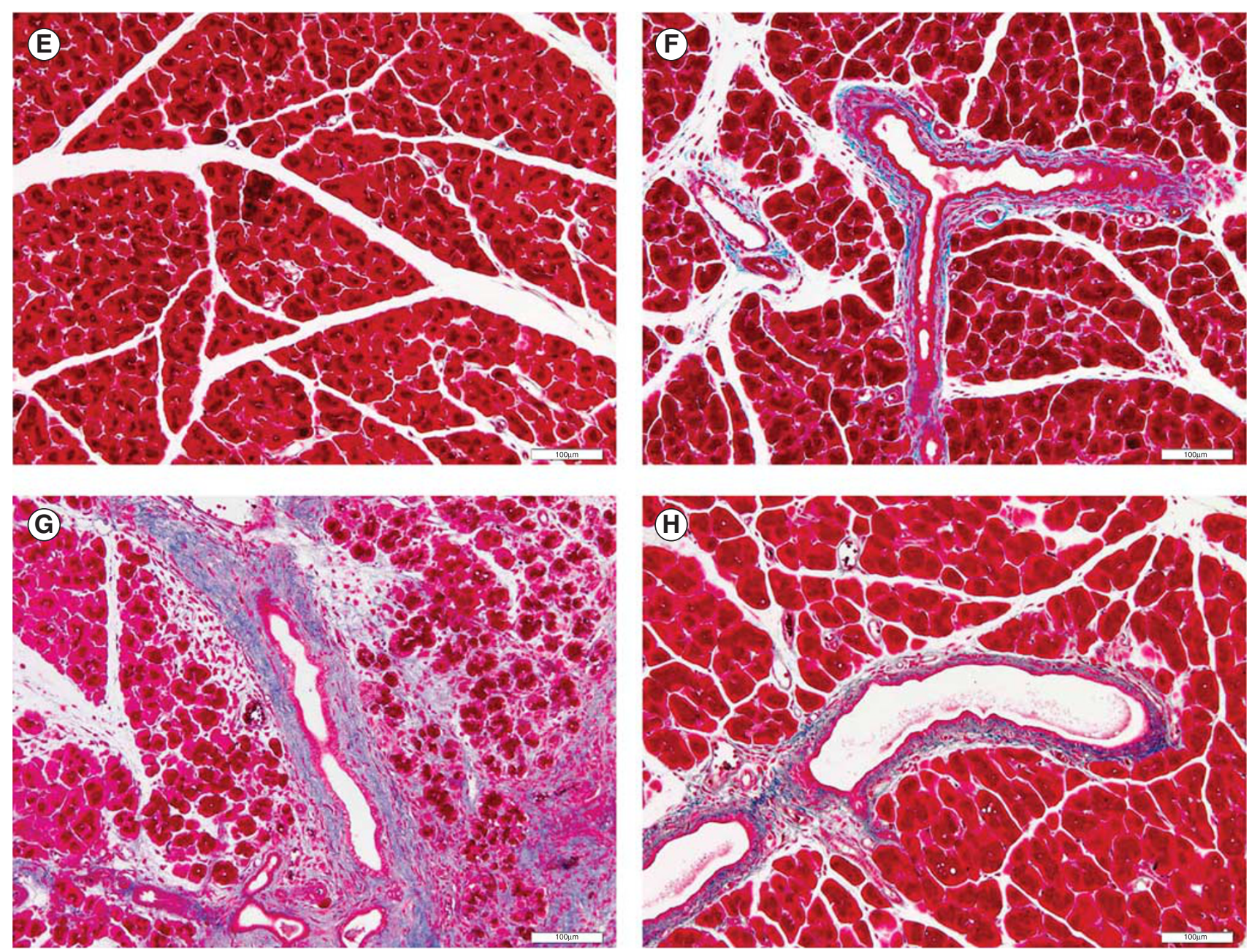

Figure 7 Continued.

pravastatin downregulated the expression levels of TNF- $\alpha$ and TGF- $\beta 1$ mRNA compared with the PDH-C group. Previous studies ${ }^{25}$ showed that TNF- $\alpha$ is a proinflammatory cytokine and is involved in the onset of pancreatitis in rats by mediating early inflammatory reactions. In addition, it is also well established that TGF- $\beta 1$ mediates fibrosis in various organs. ${ }^{26}$ Thus, it is conceivable that downregulation of the expression of these cytokines plays an important role in the attenuation of the progression of pancreatic inflammation and fibrosis by pravastatin treatment. In this study, expression level of TGF- $\beta 1$ immediately peaked after induction of $\mathrm{PDH}$, but the proportion of fibrosis progressively increased during experimental period. Previous studies have shown that TGF- $\beta 1$ plays an essential role in the induction of fibrosis, ${ }^{27}$ but other cytokines such as connective tissue growth factor (CTGF) act downstream of TGF- $\beta 1$ to also facilitate progression of fibrosis. ${ }^{28}$ It is therefore likely that expression level of TGF- $\beta 1$ did not correlate with progression of pancreatic fibrosis. For the precise mechanisms of anti-inflammatory and anti-fibrogenic actions of pravastatin, we confirmed that pravastatin exerts antioxidative action in the pancreas, as previous studies have shown. ${ }^{10,29}$ As oxidative stress has been implicated in the pathophysiology of chronic pancreatitis ${ }^{30,31}$ and antioxidant treatment can inhibit TGF- $\beta$ release and thereby suppress pancreatic inflammation and fibrosis, ${ }^{32}$ it is conceivable that pravastatin suppresses progression of pancreatic inflammation and fibrosis in this experimental model by attenuating oxidative stress. In support of our view, previous studies have shown that statins reduce fibrosis and inflammation along with an attenuation of oxidative stress in the kidney ${ }^{4}$ and heart. ${ }^{33}$

In this study, we found that treatment with pravastatin markedly increased production of IL-10 in the pancreas. IL-10 is considered to be an anti-inflammatory cytokine, because IL-10 inhibits production of various proinflammatory cytokines such as TNF- $\alpha$ and IL- 6 by monocyte, and regulates inflammatory response. ${ }^{34}$ A very recent study also showed that treatment with atorvastatin increases expression of IL-10 and then attenuates progression of glomerulonephritis. ${ }^{35}$ Therefore, our observations and previous studies suggest that overexpression of IL-10 plays an important role for anti-inflammatory and anti-fibrotic actions of pravastatin. 

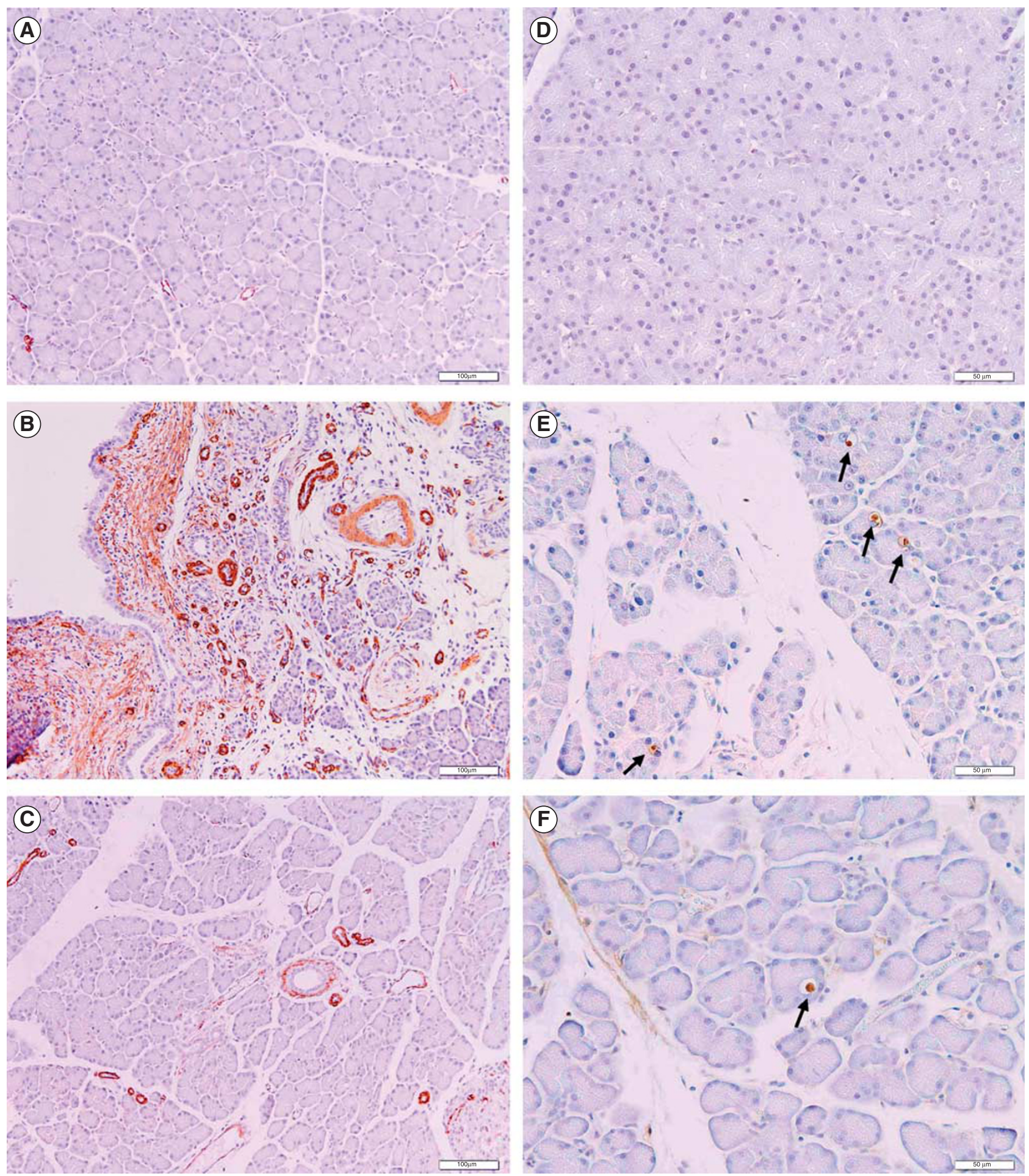

Figure 8 Immunohistochemistries for $\alpha$-smooth muscle actin $(\alpha$-SMA) $(\mathbf{A}-\mathbf{C})$ and single-stranded regions in the DNA (ss-DNA) (D-F) in the pancreas on day 14. (A) Immunoreactivity for $\alpha$-SMA was rarely noted, except in the vessel walls in the control (CONT) group. (B) In contrast, expression of $\alpha$-SMA was markedly detected in the periductal and interlobular areas in the pancreatic ductal hypertension (PDH)-C group. (C) However, $\alpha$-SMA-positive cells were slightly detected in the periacinar and interstitial areas in the PDH-P group. Original magnification, $\times 100$. Scale bar indicates $100 \mu \mathrm{m}$. (D) A minimal number of apoptotic cells were observed in the CONT group. (E) However, several apoptotic cells were distributed in one intralobular area, especially in the atrophic portion of the pancreas in the PDH-C group. (F) Few apoptotic cells were observed in several intralobular areas in the PDH-P group. An arrow shows an apoptotic cell detected with the antibody for ss-DNA. Original magnification, $\times 200$, Scale bar indicates $50 \mu \mathrm{m}$. For key to the groups, see Figure 1 . 
Table 4 Effects of pravastatin treatment on indexes of ss-DNA and 8-OHdG in the pancreas

\begin{tabular}{lccc}
\hline & CONT group & PDH-C group & PDH-P group \\
\hline Index of SS-DNA (\%) & $0.05 \pm 0.03$ & $0.29 \pm 0.10^{\mathrm{a}}$ & $0.10 \pm 0.04^{\mathrm{b}}$ \\
Index of 8-OHdG (\%) & $0.10 \pm 0.05$ & $2.63 \pm 0.50^{\mathrm{a}}$ & $0.28 \pm 0.09^{\mathrm{b}}$
\end{tabular}

Values were mean \pm s.e. of five rats. Twenty non-overlapping fields were randomly selected from five rats in each experimental group. Indexes of ss-DNA and $8-\mathrm{OHdG}$ represent the percentage of positive cells in each immunohistochemistry and indicate progression of apoptosis and oxidative stress, respectively.

${ }^{\mathrm{a}}$ Significant difference vs the value of the CONT group.

${ }^{\mathrm{b}}$ Significant difference $v$ s the value of the PDH-C group. Statistical analysis was performed by unpaired Student's $t$-test. For key to the groups, see Table 1.

Previously, PSCs were identified and characterized. ${ }^{21,36}$ PSCs are activated upon exposure to cytokines such as TGF- $\beta 1$ and TNF- $\alpha$, and then have a capacity to produce extracellular matrix proteins with an expression of $\alpha$-SMA. ${ }^{37,38}$ As treatment with pravastatin decreased the expression of $\alpha$-SMA-positive cells, it is quite possible that pravastatin prevents activation of PSCs and thereby attenuates progression of pancreatic fibrosis. Recently, an experimental study showed that green tea polyphenol prevents ethanol-induced activation of PSCs, and inhibits TGF- $\beta 1$ secretion and collagen production from PSCs by its anti-oxidative effect. ${ }^{39}$ Taken together, our results suggest that treatment with pravastatin prevented the progression of pancreatic inflammation and fibrosis by reducing activation of PSCs through its anti-oxidative effect. Previous experimental studies in vitro ${ }^{40,41}$ have shown that statins inhibit activation of fibroblasts and reduce expression of CTGF from fibroblasts through the interruption of Ras signaling and suppression of translocation of RhoA to cellular membrane. These observations suggest that statins also exert direct beneficial actions on PSCs.

This study revealed that treatment with pravastatin suppressed apoptosis in the pancreas. In support of these observations, pravastatin treatment significantly increased pancreatic weight, and contents of DNA and protein compared with the PDH group. As oxidative stress ${ }^{42}$ and inflammatory mediators such as TGF- $\beta 1$ and TNF- $\alpha^{43}$ strongly induce apoptosis, it seems likely that pravastatin inhibits apoptosis by its anti-oxidative and anti-inflammatory actions.

Pravastatin treatment significantly improved pancreatic secretory function in response to secretin stimulation. As treatment with pravastatin markedly attenuated progression of fibrosis and atrophy of the pancreas, improved pancreatic secretory function could be attributable to the maintenance of pancreatic exocrine glands by anti-inflammatory and antifibrotic actions of pravastatin. Although the $\mathrm{PDH}-\mathrm{C}$ group significantly lost body weight during experimental period, treatment with pravastatin prevented the significant decrease
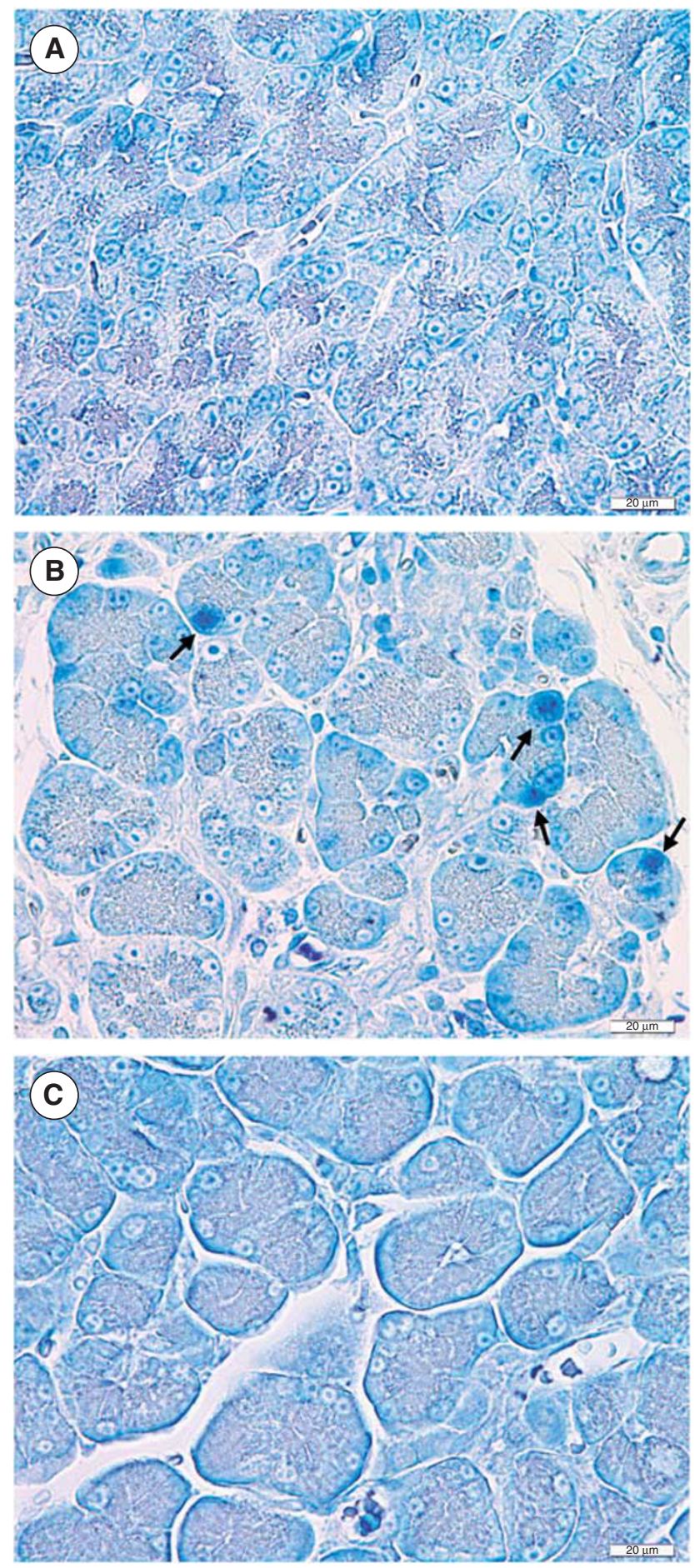

Figure 9 Immunohistochemistry for 8-hydroxy-2'-deoxyguanosine (8-OHdG) in the pancreas on day 14. (A) Immunoreactivity of 8-OHdG was rarely detected in the control (CONT) group. (B) In contrast, intense immunoreactivity of 8-OHdG was observed in the nuclei of acinar cells, especially in the atrophic lesions in the pancreatic ductal hypertension (PDH)-C group. (C) However, nuclear staining of 8-OHdG was slightly detected in the PDH-P group. Original magnification, $\times 400$. Scale bar indicates $20 \mu \mathrm{m}$. For key to the groups, see Figure 1. 
in the body weight. As there was no significant difference in the average daily food intake among three experimental groups, it is conceivable that treatment with pravastatin prevented body weight loss by improving pancreatic exocrine dysfunction and reducing maldigestion and malabsorption. On the other hand, this experimental model of chronic pancreatitis model shows only little endocrine insufficiency, ${ }^{11}$ probably because PDH does not cause inflammation and fibrosis in the islets is due to the different anatomical location from exocrine glands. Therefore, effect of pravastatin on pancreatic endocrine insufficiency was not examined in this study. However, experimental and clinical studies ${ }^{10,44}$ showed that treatment with statins improve insulin secretory function and insulin sensitivity. These observations suggest that pravastatin exerts beneficial actions on endocrine dysfunction secondary to chronic pancreatitis.

To our knowledge, very limited experimental studies examined the therapeutic effect of statins on fibrosis in the organs. ${ }^{45,46}$ Haydont et $a l^{45}$ reported that pravastatin exerts an anti-fibrotic action on the established radiation-induced intestinal fibrosis in rats. In contrast, Chang et $a l^{46}$ showed that rosuvastatin failed to alleviate the established left ventricular hypertrophy in the hypertensive rat model, although it attenuated myocardial fibrosis and myocardial stiffness compared with untreated rats. In this study, proportion of fibrotic area gradually increased even after the commencement of pravastatin treatment, which suggests that treatment with pravastatin has limited therapeutic value in this experimental model of chronic pancreatitis. We speculated that persistence of PDH even after the commencement of pravastatin treatment results in the limitation of the therapeutic action of pravastatin in this experimental model. However, pravastatin substantially attenuated the progression of typical features of chronic pancreatitis such as pancreatic exocrine insufficiency and ongoing process of inflammation, fibrosis and apoptosis, followed by atrophy of the pancreas. These results suggest that statins exert beneficial effects on patients with chronic pancreatitis and improve its prognosis. On the other hand, a number of case reports have suggested that statins may cause acute pancreatitis (AP). ${ }^{47,48}$ However, population-based case-control studies ${ }^{49,50}$ have not supported the hypothesis of a causative effect of statins on the risk of $\mathrm{AP}$, and even indicated a mild protective effect. ${ }^{50}$ These results suggest that risk of statins to cause drug-induced pancreatitis is very limited for patients with chronic pancreatitis.

In conclusion, our experimental study clearly showed that treatment with pravastatin started after the induction of chronic pancreatitis attenuates progression of pancreatic inflammation, fibrosis, apoptosis and pancreatic exocrine insufficiency by anti-oxidative action and overproduction of IL-10 in rats. However, further studies are required to investigate other mechanisms of the beneficial effect of statins. These results support the clinical use of pravastatin for patients with chronic pancreatitis.

\section{ACKNOWLEDGEMENTS}

We thank Megumi Teramoto, Naoko Kamichi, Miyuki Sato and Yuka Katsuki for the excellent technical assistance. Dr Limin Wei was financially supported by Sasagawa Japan China Medical Association, and presently works for the department of endocrinology, Hebei general hospital in China. Email: liminwei67@yahoo.com.cn. This work was supported by Sasagawa Japan China Medical Association and Grant-in-Aid for Exploratory Research from Japan Society for the Promotion of Science (No. 17659222).

\section{DISCLOSURE/CONFLICT OF INTEREST}

The authors declare no conflict of interest.

1. Endo A, Kuroda M, Tanzawa K. Competitive inhibition of 3-hydroxy-3methylglutaryl coenzyme A reductase by ML-236A and ML-236B fungal metabolites, having hypocholesterolemic activity. FEBS Lett 1976;72:323-326.

2. Solheim S, Seljeflot I, Arnesen H, et al. Reduced levels of TNF alpha in hypercholesterolemic individuals after treatment with pravastatin for 8 weeks. Atherosclerosis 2001;157:411-415.

3. $\mathrm{Li} \mathrm{C}$, Yang $\mathrm{CW}$, Park $\mathrm{JH}$, et al. Pravastatin treatment attenuates interstitial inflammation and fibrosis in a rat model of chronic cyclosporine-induced nephropathy. Am J Physiol Renal Physiol 2004;286:F46-F57.

4. Moriyama T, Kawada N, Nagatoya K, et al. Fluvastatin suppresses oxidative stress and fibrosis in the interstitium of mouse kidneys with unilateral ureteral obstruction. Kidney Int 2001;59:2095-2103.

5. Hartner A, Klanke B, Cordasic N, et al. Statin treatment reduces glomerular inflammation and podocyte damage in rat deoxycorticosterone-acetate-salt hypertension. J Hypertens 2009;27: 376-385.

6. Joyce M, Kelly C, Winter D, et al. Pravastatin, a 3-hydroxy-3methylglutaryl coenzyme A reductase inhibitor, attenuates renal injury in an experimental model of ischemia-reperfusion. J Surg Res 2001;101:79-84.

7. $\mathrm{Ni} \mathrm{W}$, Egashira K, Kataoka C, et al. Antiinflammatory and antiarteriosclerotic actions of HMG-CoA reductase inhibitors in a rat model of chronic inhibition of nitric oxide synthesis. Circ Res 2001;89: 415-421.

8. Yu Y, Ohmori K, Chen $\mathrm{Y}$, et al. Effects of pravastatin on progression of glucose intolerance and cardiovascular remodeling in a type II diabetes model. J Am Coll Cardiol 2004;44:904-913.

9. Ercan F, Gedik N, et al. Simvastatin attenuates cisplatin-induced kidney and liver damage in rats. Toxicology 2007;230:256-264.

10. Otani $M$, Yamamoto $M$, Harada $M$, et al. Effect of long- and short-term treatments with pravastatin on diabetes mellitus and pancreatic fibrosis in the Otsuka Long-Evans Tokushima Fatty rat. Br J Pharmacol 2010;159:462-473.

11. Yamamoto $M$, Otani $M$, Otsuki M. A new model of chronic pancreatitis in rats. Am J Physiol Gastrointest Liver Physiol 2006;291:G700-G708.

12. Green GM, Nasset ES. Importance of bile in regulation of intraluminal proteolytic enzyme activities in the rat. Gastroenterology 1980;79: 695-702.

13. Lowry $\mathrm{OH}$, Rosebrough NJ, Farr $\mathrm{AL}$, et al. Protein measurement with the folin phenol reagent. J Biol Chem 1985;193:265-275.

14. Labarca C, Paigen K. A simple, rapid, and sensitive DNA assay procedure. Anal Biochem 1980;102:344-352.

15. Ceska M, Birath K, Brown B. A new and rapid method for the clinical determination of alpha-amylase activities in human serum and urine. Optimal conditions. Clin Chim Acta 1969;26:437-444.

16. Ukeda $H$, Shimamura $T$, Tsubouchi M. Spectrophotometric assay of superoxide anion formed in Maillard reaction based on highly watersoluble tetrazolium salt. Anal Sci 2002;18:1151-1154.

17. Bhatia M, Ramnath RD, Chevali $L$, et al. Treatment with bindarit, a blocker of MCP-1 synthesis, protects mice against acute pancreatitis. Am J Physiol Gastrointest Liver Physiol 2005;288:G1259-G1265.

18. Reddy GK, Enwemeka CS. A simplified method for the analysis of hydroxyproline in biological tissues. Clin Biochem 1996;29:225-229.

19. Neuman RE, Logan MA. The determination of hydroxyproline. J Biol Chem 1950;184:299-306.

20. Korc M, Chandrasekar B, Yamanaka $Y$, et al. Overexpression of the epidermal growth factor receptor in human pancreatic cancer is 
associated with concomitant increases in the levels of epidermal growth factor and transforming growth factor alpha. J Clin Invest 1992;90:1352-1360.

21. Apte MV, Haber PS, Applegate $T L$, et al. Periacinar stellate shaped cells in rat pancreas: identification, isolation, and culture. Gut 1998;43: 128-133.

22. Naruse I, Keino H, Kawarada Y. Antibody against single-stranded DNA detects both programmed cell death and drug-induced apoptosis. Histochemistry 1994;101:73-78.

23. Toyokuni S, Tanaka T, Hattori Y, et al. Quantitative immunohistochemical determination of 8-hydroxy-2'-deoxyguanosine by a monoclonal antibody N45.1: its application to ferric nitrilotriacetateinduced renal carcinogenesis model. Lab Invest 1997;76:365-374.

24. Hsu SM, Raine $L$, Fanger $H$. The use of antiavidin antibody and avidinbiotin-peroxidase complex in immunoperoxidase technics. Am J Clin Pathol 1981;75:816-821.

25. Gukovskaya AS, Gukovsky I, Zaninovic V, et al. Pancreatic acinar cells produce, release, and respond to tumor necrosis factor-alpha. Role in regulating cell death and pancreatitis. J Clin Invest 1997;100: 1853-1862.

26. Villarreal FJ, MacKenna DA, Omens JH, et al. Myocardial remodeling in hypertensive Ren-2 transgenic rats. Hypertension 1995;25: 98-104.

27. Bachem MG, Meyer D, Melchior $\mathrm{R}$, et al. Activation of rat liver perisinusoidal lipocytes by transforming growth factors derived from myofibroblastlike cells. A potential mechanism of self perpetuation in liver fibrogenesis. J Clin Invest 1992;89:19-27.

28. Oemar BS, Werner A, Garnier JM, et al. Human connective tissue growth factor is expressed in advanced atherosclerotic lesions. Circulation 1997;95:831-839.

29. Sola S, Mir MQ, Lerakis S, et al. Atorvastatin improves left ventricular systolic function and serum markers of inflammation in nonischemic heart failure. J Am Coll Cardiol 2006;47:332-337.

30. Schoenberg $\mathrm{MH}$, Büchler M, Pietrzyk $\mathrm{C}$, et al. Lipid peroxidation and glutathione metabolism in chronic pancreatitis. Pancreas 1995;10:36-43.

31. Matsumura N, Ochi K, Ichimura M, et al. Study on free radicals and pancreatic fibrosis - pancreatic fibrosis induced by repeated injections of superoxide dismutase inhibitor. Pancreas 2001;22:53-57.

32. Gómez JA, Molero X, Vaquero $\mathrm{E}$, et al. Vitamin $\mathrm{E}$ attenuates biochemical and morphological features associated with development of chronic pancreatitis. Am J Physiol Gastrointest Liver Physiol 2004;287:G162-G169.

33. Habibi J, Whaley-Connell A, Qazi MA, et al. Rosuvastatin, a 3-hydroxy-3methylglutaryl coenzyme a reductase inhibitor, decreases cardiac oxidative stress and remodeling in Ren 2 transgenic rats. Endocrinology 2007;148:2181-2188.

34. de Waal Malefyt R, Abrams J, Bennett B, et al. Interleukin 10 (IL-10) inhibits cytokine synthesis by human monocytes: an autoregulatory role of IL-10 produced by monocytes. J Exp Med 1991;174: $1209-1220$.
35. Eller $\mathrm{P}$, Eller $\mathrm{K}$, Wolf $\mathrm{AM}$, et al. Atorvastatin attenuates murine antiglomerular basement membrane glomerulonephritis. Kidney Int 2010;77:428-435.

36. Bachem MG, Schneider E, Gross $H$, et al. Identification, culture, and characterization of pancreatic stellate cells in rats and humans. Gastroenterology 1998;115:421-432.

37. Apte MV, Haber PS, Darby SJ, et al. Pancreatic stellate cells are activated by proinflammatory cytokines: implications for pancreatic fibrogenesis. Gut 1999;44:534-541.

38. Mews $P$, Phillips $P$, Fahmy $R$, et al. Pancreatic stellate cells respond to inflammatory cytokines: potential role in chronic pancreatitis. Gut 2002;50:535-541.

39. Asaumi H, Watanabe S, Taguchi M, et al. Green tea polyphenol (-)epigallocatechin-3-gallate inhibits ethanol-induced activation of pancreatic stellate cells. Eur J Clin Invest 2006;36:113-122.

40. Eberlein M, Heusinger-Ribeiro J, Goppelt-Struebe M. Rho-dependent inhibition of the induction of connective tissue growth factor (CTGF) by HMG CoA reductase inhibitors (statins). Br J Pharmacol 2001;133: 1172-1180.

41. Jaster R, Brock P, Sparmann G, et al. Inhibition of pancreatic stellate cell activation by the hydroxymethylglutaryl coenzyme $A$ reductase inhibitor lovastatin. Biochem Pharmacol 2003;65:1295-1303.

42. Manna SK, Zhang HJ, Yan T, et al. Overexpression of manganese superoxide dismutase suppresses tumor necrosis factor-induced apoptosis and activation of nuclear transcription factor-kappaB and activated protein-1. J Biol Chem 1998;273:13245-13254.

43. Zhang $X P$, Lin $Q$, Zhou YF. Progress of study on the relationship between mediators of inflammation and apoptosis in acute pancreatitis. Dig Dis Sci 2007;52:1199-1205.

44. Paniagua JA, Lopez-Miranda J, Escribano A, et al. Cerivastatin improves insulin sensitivity and insulin secretion in early-state obese type 2 diabetes. Diabetes 2002;51:2596-2603.

45. Haydont V, Bourgier C, Pocard M, et al. Pravastatin Inhibits the Rho/ CCN2/extracellular matrix cascade in human fibrosis explants and improves radiation-induced intestinal fibrosis in rats. Clin Cancer Res 2007;13:5331-5340.

46. Chang SA, Kim YJ, Lee HW, et al. Effect of rosuvastatin on cardiac remodeling, function, and progression to heart failure in hypertensive heart with established left ventricular hypertrophy. Hypertension 2009;54:591-597.

47. Tsigrelis C, Pitchumoni CS. Pravastatin: a potential cause for acute pancreatitis. World J Gastroenterol 2006;12:7055-7057.

48. Anagnostopoulos GK, Tsiakos S, Margantinis G, et al. Acute pancreatitis due to pravastatin therapy. JOP 2003;4:129-132.

49. Lancashire RJ, Cheng K, Langman MJ. Discrepancies between population-based data and adverse reaction reports in assessing drugs as causes of acute pancreatitis. Aliment Pharmacol Ther 2003;17:887-893.

50. Thisted H, Jacobsen J, Munk EM, et al. Statins and the risk of acute pancreatitis: a population-based case-control study. Aliment Pharmacol Ther 2006;23:185-190. 